\title{
Moulins-sur-Céphons, les Vaux
}

$\mathrm{n}^{\circ} 064476$

\section{Tony Hamon et Sophie Krausz}

\section{(2) OpenEdition \\ 12 Journals}

Édition électronique

URL : http://journals.openedition.org/adlfi/14044

ISSN : 2114-0502

Éditeur

Ministère de la culture

Référence électronique

Tony Hamon et Sophie Krausz, " Moulins-sur-Céphons, les Vaux », ADLFI. Archéologie de la France Informations [En ligne], Centre, mis en ligne le 03 mars 2015, consulté le 30 avril 2019. URL : http:// journals.openedition.org/adlfi/14044

Ce document a été généré automatiquement le 30 avril 2019.

(c) Ministère de la Culture et de la Communication, CNRS 


\title{
Moulins-sur-Céphons, les Vaux
}

\author{
$n^{\circ} 064476$
}

\author{
Tony Hamon et Sophie Krausz
}

Lien Atlas (MCC) :

http://atlas.patrimoines.culture.fr/atlas/trunk/index.php?

ap_theme=DOM_2.01.02\&ap_bbox=1.509;46.970;1.618;47.042

1 Le site se trouve en Champagne berrichonne, sur la commune de Moulins-sur-Céphons, à $5 \mathrm{~km}$ de la ville de Levroux, mais en limite de cette commune (Indre). Le gisement est installé sur le versant ouest d'une croupe calcaire, en contrebas duquel coule le ruisseau «la Céphons ».

2 Le gisement des Vaux est constitué de trois bâtiments et d'une palissade visibles sur les clichés aériens. Les témoins sont répartis sur une surface de trois hectares. Le gisement a été découvert lors d'une campagne aérienne en 1984. La campagne 1998 a porté sur le plus grand bâtiment (bâtiment 1) remarqué, en continuité d'un sondage pratiqué en 1987. À la lecture des clichés, le bâtiment est visible sur une soixantaine de mètres de longueur, à cheval sur trois parcelles différentes. Aucun des pignons n'est visible. L'un se perd sous les constructions de la ferme des Vaux, le second semble être construit à l'endroit d'une veine d'argile peu réceptive à la lecture aérienne.

3 Cette année, $2660 \mathrm{~m}^{2}$ ont été décapés dans une seule parcelle et $1000 \mathrm{~m}^{2}$ ont été entièrement fouillés. Après décapage, au moins deux constructions et des aménagements externes ont été mis en évidence.

4 Le bâtiment 1 découvert est constitué au centre d'une rangée de poteaux faîtiers. Un poteau faitier sur deux est la composante d'une tierce. Les murs du bâtiment sont composés de deux rangées de poteaux. Les rangées situées plus à l'extérieur sont des tranchées dans lesquelles sont disposés des poteaux calés par des blocs calcaires et de l'argile. Les deux rangées internes sont composées d'une rigole centrale agrandie tous les deux mètres pour y disposer des poteaux d'environ $1 \mathrm{~m}$ de diamètre. Une autre tranchée à poteaux a également été observée, le long de la façade sud du bâtiment, à l'extérieur. 
Accolée à la façade sud, le départ d'une tranchée pourrait correspondre à un aménagement d'entrée.

Une aire à calcaire chauffé d'environ $5 \mathrm{~m}$ de diamètre a été observée dans l'alignement des poteaux faîtiers.

6 Dans la partie nord, une série d'aménagements permet de suggérer la présence d'un autre bâtiment disposé perpendiculairement à celui connu. Une rangée de poteaux accolée à la perpendiculaire de la façade nord du bâtiment correspondrait à un pignon. L'un recoupe l'autre, mais ce secteur n'étant pas encore fouillé, nous ne pouvons préciser la stratigraphie.

7 Importante particularité, le mobilier est abondant dans certains secteurs du site. De la céramique a en effet été rencontrée à l'emplacement des poteaux de la rangée interne nord. Certains sont plus riches que d'autres. Une partie du mobilier a manifestement brûlé.

8 La céramique, essentiellement fine, appartient à la culture d'Artenac. Les décors sont absents mais les formes sont caractéristiques. Certains tessons pourraient être peints d'un colorant rouge.

\section{INDEX}

Index chronologique : Néolithique

Index géographique : Centre, Indre (36), Moulins-sur-Céphons

operation Fouille programmée (FP)

Mots-clés : bâtiment, poteaux, céramique 